\title{
MCHQ-Alfa: Uma Proposta de Ferramenta para Aprendizagem da Língua Portuguesa na Educação de Surdos Utilizando o Potencial das Histórias em Quadrinhos Mediada por Mapa Conceitual
}

Maria Andréia Rodrigues dos Santos - UFPA - Universidade Federal do Pará andreia.santos@ifpa.edu.br

Eloi Luiz Favero - UFPA - Universidade Federal do Pará

favero@ufpa.br

Resumo. Este artigo apresenta a proposta de uma ferramenta voltada para a aprendizagem da Língua Portuguesa na Educação de Surdos. Esta proposta foi sustentada por um estudo da literatura existente na área, bem como pelas necessidades reais do Instituto Felipe Smaldone (IFS) em Belém/Pa. O MCHQ-Alfa é uma ferramenta lúdica que permite a construção de mapas conceituais e histórias em quadrinhos. Esta construção está organizada em níveis crescente de dificuldades $e$ apresenta auxílio de recursos como imagens, vídeos em LIBRAS e a datilologia. O aluno poderá desenvolver seu mapa conceitual sobre um assunto previamente estudado, em seguida será possível criar sua história em quadrinhos, estimulando assim o fortalecimento de seu vocabulário, bem como sua produção textual.

Palavras-chave. educação especial, informática na educação de surdos, ferramenta inclusiva, histórias em quadrinhos, mapa conceitual.

\section{MCHQ-Alfa: A Proposal of a Tool for Learning the Portuguese Language in Deaf Education Using the Potential of Mediated Comics Conceptual Map}

Abstract. This paper presents a proposal of a focused tool for learning the Portuguese Language in Deaf Education. This proposal was supported by a study of the existing literature in the area, as well as by the actual needs of the Institute Felipe Smaldone (IFS) in Belém / Pa. The MCHQ-Alfa is a fun tool that allows the construction of concept maps and comics. This construction is organized in increasing levels of difficulty and provides aid resources such as images, videos (Libras) and dactylology. The student can develop your concept map on a subject previously studied, then you can create your comics, thus stimulating the strengthening of their vocabulary as well as its textual production.

Keywords. special education, informatics in deaf education, inclusive tool, comics, concept map.

\section{Introdução}

A utilização dos recursos tecnológicos no processo de ensino-aprendizagem evidencia novas formas no fazer educacional, onde é necessário respeitar o processo de aprendizagem individual e coletivo, como forma humanizada de assimilação e acomodação do conhecimento. Goldschmidt (2011) atestam o que diz (Renato, Eduardo José. Informática e Educação,1997,05), isto só terá sentido se forem assegurados os princípios universais que regem a busca do processo de humanização.

Apenas a inserção de novos recursos tecnológicos no processo de ensinoaprendizagem não indica maior qualidade na educação, é preciso considerar que cada indivíduo traz consigo suas histórias, vivências e conhecimento já construído que servirá de ponte para novas descobertas.

Apesar da grande utilização desses recursos, devemos encarar esta situação como possíveis mudanças na qualidade do ensino e não como solução para toda 
problemática existente na educação de surdos, este trabalho utilizará o termo surdo referindo-se tanto a surdos como a pessoas portadoras de deficiência auditiva.

Na educação de surdos, os recursos tecnológicos aliados a estratégias educativas adequadas fomentam o aprender de forma interativa, uma vez que é necessário reconhecer as potencialidades da tecnologia e tomar consciência da realidade em que a escola está inserida, evitando assim, a mera informatização do ensino.

Diante disto, devemos considerar que Melo (2007), Piccolo et al (2007), salientam que é de cunho relevante a preocupação com as diretrizes de acessibilidade em recursos tecnológicos inclusivos, trazendo assim aspectos facilitadores na educação de surdos. A inserção da acessibilidade nos recursos tecnológicos é um viés a ser seguido, investigando como contemplar de forma efetiva os recursos tecnológicos inclusivos.

Como grande parte das crianças surdas não tem um contato efetivo com a língua de seus familiares ouvintes, no nosso caso a Língua Portuguesa (L2 - Segunda língua), elas acabam não apresentando, em seus primeiros anos de escola, uma língua constituída que sirva de base para que possa construir na escrita Pereira (2009).

A criança ouvinte, no início da sua infância, começa sua comunicação por balbucios, gestos e meios sonoros que irá constituir a língua base sugerida acima. Isto não acontece com parte das crianças surdas filhas de pais ouvintes, acarretando a permanência dessas crianças em séries iniciais, com limitação de vocabulário e grande dificuldade de socialização, dificultando que esta criança se encontre com sua própria identidade, a identidade surda Quadros (1997).

Quadros (1997), Góes (1999) apresentam as dificuldades encontradas por surdos no que tange o aprendizado da leitura e escrita da Língua Portuguesa (L2), pois para que haja um domínio da escrita é necessário um conhecimento prévio da L2 que para os surdos não acontece de forma similar aos ouvintes. Este fato representa claramente a interferência da Língua de Sinais (L1 - Primeira língua/língua materna); no Brasil Língua Brasileira de Sinais (LIBRAS) na L2, ou seja, o surdo não formou sua visão de mundo, na maioria dos casos, na sua língua de aprendizado natural.

Para Dizeu e Caporali (2005) a língua de sinais apresenta o campo gesto-visual como principal meio propagador. Neste sentido devemos considerar que para o surdo, o canal visual é o principal meio de apropriação de conhecimento e é nesta lacuna que os recursos tecnológicos tornam-se recursos relevantes no processo de aprendizagem e assim com recursos visuais e interativos se quer transformar o aprender do surdo.

\section{Aspectos Abordados na Concepção da Proposta}

Considerando que o tema estudado neste trabalho envolve diferentes aspectos de pesquisas científicas como Língua Portuguesa, Língua de Sinais, surdez e educação, editores de histórias em quadrinhos e mapas conceituais na educação, julgou-se explanar estes aspectos a seguir.

\subsection{Bilinguismo e Educação de Surdos}

Quadros (1997) comenta a permanência de parte das crianças surdas em série iniciais, devido esta falta de contato com a L1, isto decorre em limitação de vocabulário, confusão no significado de tais vocábulos, dificuldade de socialização, permanência dessas crianças em séries iniciais, índice de baixa estima elevado por parte destas crianças, desmotivando a mesma no decorrer de seus anos escolares.

Neste sentido, Dizeu e Caporali (2005) defendem: 
“[...]o sujeito deve adquirir a língua de sinais, como primeira língua, de forma natural e uma segunda língua, a língua da sociedade ouvinte majoritária (oral e/ou escrita), construídas por intermédio das bases linguísticas obtidas por meio da língua de sinais. ”

Segundo Pereira (2009) muitas instituições têm adotado uma proposta bilíngue na educação de surdos, devido dois fatores, o reconhecimento claro de que a L1 está diretamente ligada ao desenvolvimento cognitivo, afetivo, social e linguístico dos surdos e as reivindicações de comunidades surdas em utilizar a L1, aspecto também considerado por Quadros (2005), o desejo dos surdos em aprender na L1, evidenciando assim, a verdadeira identidade da pessoa surda.

Diante da problemática que Pereira (2009) denota, ou seja, grande parte das crianças surdas não tem contato efetivo com a L1, logo o seu processo de aprendizagem fica fragilizado quando o indivíduo, decorrente de sua limitação de comunicação com os membros de seu convívio familiar, não constituiu de forma satisfatória as experiências naturais dos anos iniciais de sua vida.

Sobre este aspecto encontramos trabalhos como Campos et al (2001), Carvalho \& Ferreira (2011), Valentini et al (2006), Lorenzini \& Neto (2009), Castro Junior et al (2008), Sousa (2010), que trazem como interesse a aquisição da língua portuguesa na educação de surdos, bem como a língua de sinais, ou seja, a aquisição da L1 e L2 por parte dos alunos surdos.

\subsection{História em Quadrinhos na Educação}

Segundo os Parâmetros Curriculares Nacionais (PCN, 1997): língua portuguesa, os quadrinhos, revistas, suplementos infantis e dentre outros figuram na lista de gêneros adequados para o trabalho com a linguagem escrita.

O fato de associar imagens a textos leva algumas crianças que ainda não estão familiarizadas com a leitura, a deduzir o significado das histórias, pois passam a observar as imagens e muitas vezes entendem o assunto tratado, este é um dos motivos que pesquisas acadêmicas sugerem a utilização das histórias em quadrinhos (HQ) em sala de aula, pois dessa forma proporcionam facilidades no entendimento do assunto e desenvolvimento da criatividade, é o que pode ser encontrado em Piconi e Tanaka (2003), Boff e Giraffa (2000).

Sobre este aspecto encontramos Bim (2001), Tanaka (2004), Boff \& Giraffa (2000), que trazem como interesse utilizar a potencialidade das HQ na alfabetização de surdos, explorar o campo visual da criança surda e estimular a criatividade, bem como a construção de sua visão de mundo como indivíduo ativo na sociedade.

\subsection{Mapa Conceitual como ferramenta cognitiva}

Considerando a potencialidade da imagem e toda a mensagem visual que esta traz consigo, crianças não familiarizadas com a leitura e escrita, muitas vezes, conseguem absorver o significado da mensagem que está sendo apresentada, este fato afirma a sugestão de pesquisadores quando mencionam a utilização das histórias em quadrinhos em sala de aula. Diante da situação proposta e assertiva levantada, leva-nos a lançar mão de representações gráficas de conceitos e relacionamentos hierárquicos, onde a construção visual alicerça o conhecimento de um indivíduo em sua estrutura cognitiva, segundo Novak (1997) a ferramenta cognitiva, mapa conceitual (MC) propõe este cenário. 
Segundo Novak (1997) a ferramenta cognitiva, MC, propõe organizar e representar o conhecimento, esta ferramenta baseia-se em representações gráficas de conceitos de um determinado assunto estudado, bem como seus relacionamentos hierárquicos. Diante disto, há uma forte corrente para que o indivíduo construa seu próprio conhecimento através de um processo cognitivo que respeite a realidade em que o indivíduo está inserido.

Sobre este aspecto encontramos Souza \& Boruchovitch (2010), Oliveira et al (2008), Grillo \& Lima (2008), Gava, Menezes \& Cury (2000), que trazem como interesse a utilização de uma ferramenta cognitiva que auxilie na educação. Estas pesquisas lançam uma reflexão sobre a utilização de MC como estratégia de ensinoaprendizagem, bem como figurando como ferramenta avaliativa.

\subsection{Acessibilidade na Realidade Surda}

Embora seja incontestável a presença de esforços para sanar lacunas existentes em relação à acessibilidade nos sistemas educacionais (propondo ferramentas visuais que facilitam e estimulam o raciocínio de um indivíduo surdo), faz-se necessário evidenciar a preocupação do desenvolvimento de uma proposta com interfaces acessíveis a realidade do indivíduo surdo, fazendo uso de imagens, vídeos e datilologia nas interfaces para colocar este indivíduo em contato com sua língua materna e servir de âncora para a aprendizagem da L2.

Nesta perspectiva, o presente trabalho procura utilizar recursos semióticos como vídeos em libras, imagens, soletração manual, utilizando alfabeto datilológico, ou seja, utilizando o sistema de representação de letras do alfabeto manual, usando só as mãos; para que o aluno se apoie em sua língua de instrução e no seu universo espaço-visual.

Sobre este aspecto encontramos Abreu (2010), Melo (2007), Piccolo et al (2007) que para tanto, considerou-se o levantamento de diretrizes de acessibilidade encontradas em W3C ${ }^{1}$ (2008) apud Abreu, Pollyanna M. de, apesar das diretrizes tratadas em W3C não serem específicas para usuários surdos, mas foi de grande valia para a pesquisa e serviu como ponto de partida; considerou-se também um conjunto de recomendações de acessibilidade para auxiliar a construção de ferramentas educacionais encontradas no trabalho de Abreu (2010) construída através de um levantamento específico sobre as necessidades para sistemas de alfabetização de crianças surdas.

\section{Proposta do MCHQ-Alfa e Arquitetura}

Esta proposta apresenta uma abordagem bilíngue na educação de surdos, onde a L1 exerce o papel de primeira língua, permitindo à criança surda ter acesso a sua comunidade e a L2 passa a ser vista como uma segunda língua que permitirá a solidificação das estruturas linguísticas. Estes aspectos são apresentados em Quadros (2005), Pereira (2009).

Kubaski e Moraes (2009) defendem a importância das duas línguas estarem interligadas na educação do surdo, mas não simultaneamente. Nesta perspectiva, é lançado o reconhecimento necessário de uma educação específica.

É neste contexto que o presente estudo vislumbra a proposta de um recurso de aprendizagem a fim de auxiliar na aprendizagem da L2 utilizando editor de HQ mediado por MC. Tal recurso a ser proposto está sendo validado através de um software educativo, bem como uma proposta metodológica que proporcione auxílio no processo de ensino-aprendizagem na educação de surdos, respeitando a abordagem bilingue e as diretrizes de acessibilidade. 
A ferramenta proposta possui duas visões de acesso (ver Figura 1), a visão do educador e a visão do aluno. A composição da visão do educador consiste em criar a atividade proposta de acordo com o assunto apresentado (utilizando o Gerenciador de Atividades), ou seja, informar o texto a ser trabalhado, bem como as categorias de imagens que os alunos terão acesso na atividade (estas categorias devem está relacionadas com o texto previamente informado), informar a quantidade e nome dos alunos (participantes) que aquela atividade terá, para que seja possível o monitoramento e acompanhamento do aprendizado por parte do educador, ainda na visão do educador temos a inserção, alteração e exclusão de imagens, vídeos e datilologia dos objetos no repositório. Nesta visão também é possível saber quantos usuários estão conectados, bem como em que etapa se encontra cada usuário, e é possível a visualização de uma etapa concluída ou inacabada por parte do aluno (utilizando o Visualizador de Monitoramento), dessa forma o educador poderá auxiliar o aluno quando necessário e finalmente o educador também tem acesso a uma espécie de log de cada aluno (será gravado histórico de todas as interações realizadas pelos alunos). A gravação do arquivo de histórico acontecerá desde o momento em que o aluno se credencia na aplicação. Este recurso auxilia o educador na avaliação do aluno e no reconhecimento do processo cognitivo do aluno.

A composição da visão do aluno consiste em acessar a atividade previamente criada (através da interface de credenciamento). É neste momento que o aluno tem a possibilidade de reconhecer seu sinal, bem como a cor em que foi atribuída a ele previamente pelo educador. Na verificação dessas credenciais do aluno, cada usuário é validado uma única vez. A ferramenta aqui proposta procura fornecer certa autonomia, no momento que o aluno inicia o acesso as atividades. Procurou-se garantir que o próprio aluno acessasse a ferramenta através um conjunto equivalente de alternativas, fornecido pela ferramenta, tais como: reconhecer seu sinal em libras, identificação do nome em português associado com a datilologia do nome ou a cor que o educador atribuiu e já trabalhou previamente com o aluno em sala de aula. É necessário ressaltar que a utilização da biometria é uma alternativa para fornecer maior segurança a esta funcionalidade, este recurso não está sendo contemplado nesta versão, mas poderá ser inserido em trabalhos futuros.

Nesta visão o aluno toma ciência do conjunto de atividades que deverá ser trabalhada por ele, estas atividades estão dispostas da seguinte forma: a) construção de MC de um determinado texto apresentado previamente pelo educador de acordo com a contextualização aplicada, adequando assim à realidade da classe em questão (a construção deste MC é apoiada por datilologia na interface, bem como palavras em português, elementos visuais com parâmetros da língua de sinais, associando estes a movimentos das mãos, pontos de articulações aliados a expressões faciais), (ver Figura 2); b) a obtenção dos objetos para a elaboração da HQ por parte do aluno se dará de forma automática a partir da construção do MC da fase anterior, a construção da HQ deve ser elaborada pelo aluno, a partir de conceitos utilizados na construção do MC (tais como, personagens, balões, cenários, animais, frutas e outros objetos visuais), bem como será possível a constatação da produção de texto por parte do aluno. 


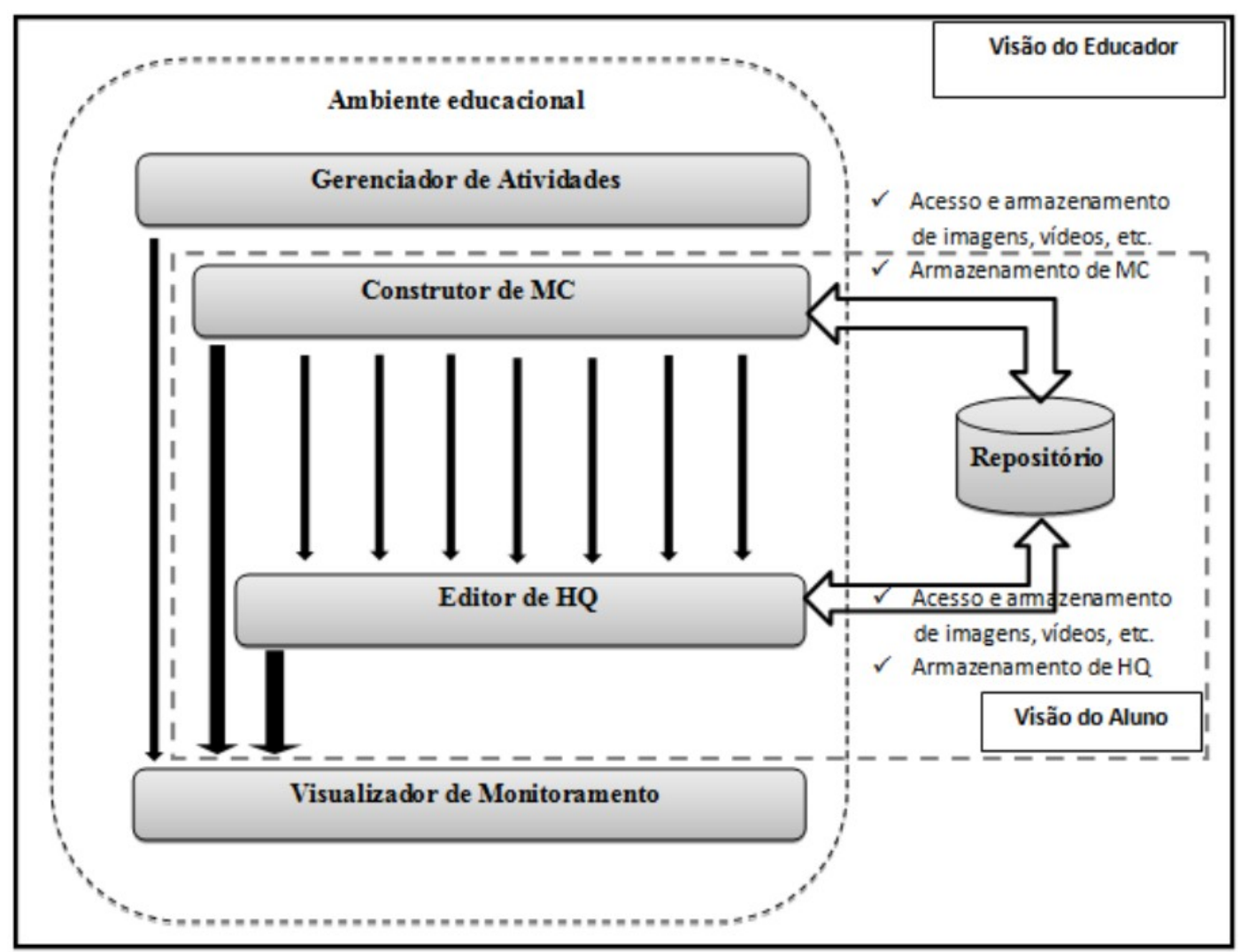

Figura 1 - Arquitetura da ferramenta proposta

O protótipo foi baseado no modelo cliente/servidor. A aplicação cliente e a aplicação servidora, que repassa as informações à aplicação cliente foram desenvolvidas em Java, com comunicação sob protocolo TCP/IP.

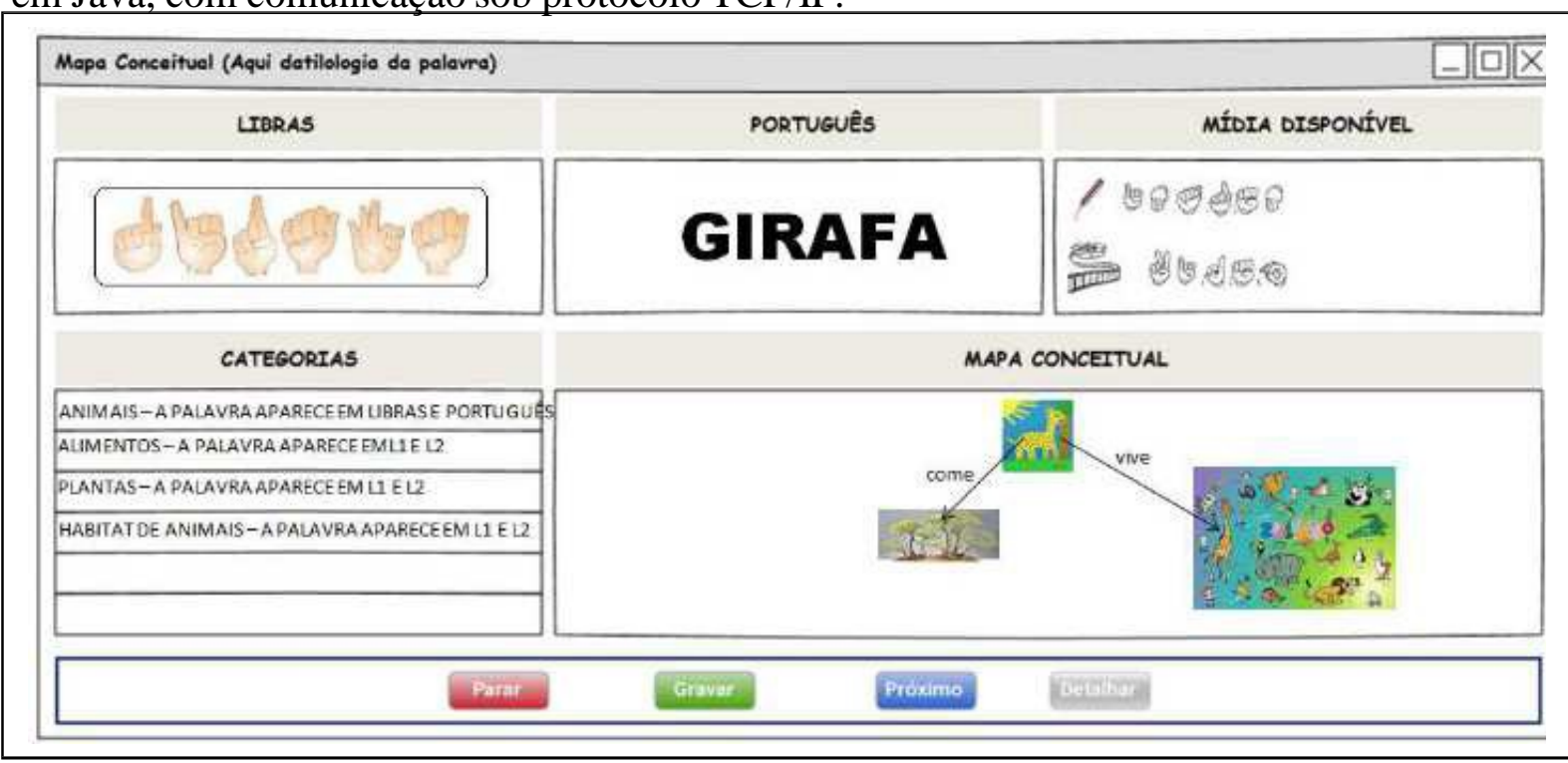

Figura 2 - Protótipo da tela para construção de MC 


\section{Resultados Esperados}

De acordo com a contextualização realizada, o trabalho traz o desejo de estreitar a lacuna hoje existente no que tange a aprendizagem da Língua Portuguesa na educação de surdos. O recurso aqui proposto procura proporcionar auxílio no processo de ensinoaprendizagem na educação de surdos, respeitando a abordagem bilíngue e as diretrizes de acessibilidade.

Espera-se oferecer um ambiente de fácil utilização tanto pelo aluno como pelo educador, que o ambiente possa permitir adequação significativa ao tipo de atividade realizada em sala de aula, que de acordo com o cenário proposto proporcione estimular o raciocínio do aluno, bem como respeitando o conhecimento previamente adquirido.

Através deste ambiente espera-se inclusive que os alunos tenham a possibilidade de criar seus mapas conceituais de acordo com sua estrutura cognitiva, considerando o que foi apresentado em sala de aula e a partir destes mapas tenham a possibilidade de criar suas histórias, bem como seus próprios textos.

Fornecer várias formas do conteúdo estudado, ou seja, conteúdo textual e não textual como imagens, vídeos, soletração manual; oportunizar as várias maneiras de leitura do conteúdo estudado através do texto, vídeo em Libras, imagens associadas e uso de datilologia; fornecer uma interface que esteja imersa a realidade do surdo, proporcionando a independência do usuário surdo desde o credenciamento do mesmo ao acessar a ferramenta bem como na utilização da mesma.

Para que seja possível a validação do trabalho aqui apresentado, está sendo aplicado o seguinte esquema: No primeiro momento, foi realizado procedimento científico de investigação, a observação sem a ferramenta proposta. Esta observação aconteceu no Instituto Felipe Smaldone - por ser uma escola especializada de surdos e ser local de apoio pedagógico para alunos surdos utilizando abordagem bilíngue - com alunos participantes do Programa de Alfabetização (alunos de escolas regulares que recebem atendimento pedagógico na instituição por parte de professores do ciclo itinerante).

O propósito da observação foi captar toda e qualquer informação relevante para compreender o processo de aprendizagem na educação de surdos. Foi respeitada a proposta pedagógica aplicada pelo educador em sala de aula, ou seja, foram observadas atividades referentes à aprendizagem, a reação dos alunos, como acontecia a comunicação entre os indivíduos, se a atividade proposta era realizada por parte dos alunos, com ou sem o auxílio do educador, do computador, dos colegas entre si.

O período para realização da observação e o número de períodos não foram estabelecidos previamente, foi finalizada quando se verificou que as informações se tornaram reincidentes e deram mostras de exaustão. Esta fase foi finalizada.

No segundo momento, está sendo realizada coleta de dados que possa dar indícios para que seja possível a validação do ambiente, e para tanto foi disponibilizado o protótipo da ferramenta nas máquinas do laboratório disponível no IFS, onde os indivíduos observados são os mesmos do primeiro momento, bem como os mesmos educadores. Esta fase está em andamento.

No terceiro momento, será possível realizar comparações entre os cenários propostos, com e sem o ambiente em sala de aula, podendo assim coletar resultados preliminares deste estudo.

\section{Considerações finais}

É incontestável a inserção de novos recursos tecnológicos no apoio a educação especial, e que neste trabalho, está voltado para a educação de surdos. Sempre 
ressaltando que esta inserção não surtirá efeito de forma isolada, mas sim deve ser apoiada por estratégias educativas adequadas.

Pesquisas como esta podem contribuir positivamente na tentativa de fornecer apoio instrumental para modificar o cenário no que tange tais aspectos como: permanência dos alunos em séries iniciais, limitação de vocabulário e grande dificuldade de socialização. Aqui são apresentados alguns aspectos para a modificação desse cenário, tais como: estimular o raciocínio e criatividade através deste novo ferramental em conjunto com estratégias adequadas proposta pelo profissional de educação, ampliar o vocabulário situando o aluno em sua língua materna, bem como oferecer ambiente visual adequado e estimulante para o desenvolvimento de sua estrutura cognitiva e finalmente proporcionar o contato com seus pares durante a atividade que venha a ser proposta.

1 O Consórcio World Wide Web (W3C) é um consórcio internacional no qual organizações filiadas, uma equipe em tempo integral e o público trabalham juntos para desenvolver padrões para a Web. A missão do W3C é conduzir a World Wide Web para que atinja todo seu potencial, desenvolvendo protocolos e diretrizes que garantam seu crescimento de longo prazo. Basicamente, o W3C cumpre sua missão com a criação de padrões e diretrizes para a Web. Desde 1994, o W3C publicou mais de 110 desses padrões, denominados Recomendações do W3C. - fonte: http://www.w3c.br/sobre/ (acessado em: 07/01/2013).

\section{Referências Bibliográficas}

ABREU, P. M. de. Recomendações para projetos de TICs para apoio a alfabetização com Libras, UFMG, Belo Horizonte, agosto de 2010. Dissertação de Mestrado.

BIM, S. A. HagáQuê Editor de Histórias em Quadrinhos, Universidade Estadual de Campinas. 2001. Dissertação de Mestrado.

BOFF, E.; GIRAFFA, L. M. M. A cooperative environment on the Web to support teaching-learning activities. In: ICECE 2000 (International Conference on Engeneering and Computer Education), São Paulo, SP. Proceedings... São Paulo, IEEE (Institute of Electrical and Electronics Engineers).

CAMPOS, M. B.; GIRAFFA, L. M. M.; SANTAROSA, L. M. C. Tecnologia em Apoio à Educação Bilingue de Surdos: Comunicação e Aprendizagem. Faculdade de Informática - FACIN - PUCRS, 2001. Porto Alegre -RS - Brasil.

CARVALHO, N. A.; FERREIRA, B. de J. "Especificação e Desenvolvimento de uma Ferramenta voltada ao amadurecimento do vocabulário de crianças surdas”. In: XVII WIE - Workshop em Informática na Escola / XXII Simpósio Brasileiro de Informática na Escola, 2011, Aracaju - SE: Sociedade Brasileira Computação.

CASTRO JUNIOR, H. P. de; ALMEIDA, J. M. de; MONTENEGRO, K. S.; OLIVEIRA, A. I. A. de. O software "Brincando com leitura": estimulação de habilidades para a aprendizagem de leitura e escrita de crianças com deficiência. In: Anais do XXVIII Congresso da SBC/WIE - Workshop sobre Informática na Escola. 2008. 
DIZEU, L. C. T.; CAPORALI, S. A. A Língua de Sinais Constituindo o Surdo como Sujeito. Educ. Soc. Campinas, VOL. 26, N. 91, P. 583-597, maio/ago de 2005, disponível em http://www.cedes.unicamp.br

GAVA, T. B. S.; MENEZES, C. S. de; CURY, D. Aplicações de Mapas Conceituais na Educação como Ferramenta MetaCognitiva - Departamento de Informática UFES - Vitória - ES - Brasil. 2000.

GÓES, M. C. R. Linguagem, Surdez e Educação. 2. ed. Campinas: Autores Associados. 1999.

GOLDSCHMIDT, R. R. Educação Superior da Faetec: muito além da sala de aula conquistas, desafios e perspectivas. Rio de Janeiro, 2011.

GRILLO, M., LIMA, V. M. do R. Mapas Conceituais e sua utilização na educação Universidade Católica do Rio Grande do sul, 2008.

KUBASKI, C., MORAES, V. P. O Bilinguismo como Proposta Educacional para Crianças Surdas - IX Congresso Nacional de Educação - EDUCERE / III Encontro Sul Brasileiro de Psicopedagogia. 26 a 29 de outubro de 2009 - PUCPR.

LORENZINI, I. P., NETO, W. C. B. Sistema Tutor Inteligente para Auxílio na Alfabetização de Crianças Surdas em um Contexto Bilíngue. Workshop sobre Informática na Educação. 2009.

MELO, A. M. Design inclusivo de sistemas de informação na web. Instituto de Computação, Universidade Estadual de Campinas, 2007. 339 p. Tese de Doutorado em Ciência da Computação).

NOVAK, J. D. A Theory of education. Ithaca, N.Y., Cornell. University Press. 1977. OLIVEIRA, G.F.; RODELlO, I. A.; BREGA, J. R. F.; SEMENTILLE, A. C. Integrando Mapas Conceituais e Recursos Multimídia em Ambientes de Realidade Virtual não Imersiva. Centro Universitário Eurípides de Marilia - Marilia/SP. UNESP Bauru/SP. SBC Anais do XXVIII Congresso da SBC WIE Workshop sobre Informática na Escola. 2008.

PCN. Parâmetros curriculares nacionais. 2. Língua portuguesa: Ensino de primeira à quarta série. 1997.

PEREIRA, M. C. da C. Leitura, escrita e surdez / Secretaria da educação. 2.ed. São Paulo. 2009: FDE, 104 p.

PICCOLO, L. S. G., MELO, A. M., BARANAUSKAS, M. C. C. Accessibility and Interactive TV: design recommendations for the Brazilian scenario. In: IFIP TC13 Conference in Human-Computer Interaction, Rio de Janeiro. 2007. Proceedings... Heidelberg: Springer. 
PICONI, A. C.; TANAKA, E. H. A Construção de Histórias em Quadrinhos Eletrônicas por Alunos Autistas, 2003 - XIV Simpósio Brasileiro de Informática na Educação SBIE - NCE/UFRJ.

QUADROS, R. M. Educação de surdos: aquisição da linguagem. São Paulo. 1997: Artes Médicas.

QUADROS, R. M. O bi do bilinguismo na educação de surdos In: Surdez e bilinguismo. $1^{\text {a }}$ ed. Porto Alegre. 2005: Editora Mediação, v.1, p. 26-36.

SOUSA, G. V. de. Ambiente Computacional para Auxiliar na Aprendizagem do Surdo, Fortaleza - Ceará, Maio. 2010.

SOUZA, N. A. de, BORUCHOVITCH, E. Mapas Conceituais: Estratégia de Ensino/Aprendizagem e Ferramenta Avaliativa - Educação em Revista, Belo Horizonte, 2010, v.26, n.03, p.195-218, dez.

TANAKA, E. H. Tornando um software acessível às pessoas com necessidades educacionais especiais - Universidade Estadual de Campinas, 2004. Dissertação de Mestrado.

VALENTINI, C. B.; BISOL, C. A.; CASA, M. E.; SGORLA, E. Um software de autoria para a educação de surdos: integração da língua de sinais e da língua escrita - Universidade de Caxias do Sul. 2006. 